\title{
The Onchocerciasis Elimination Program for the Americas: a history of partnership
}

\author{
J. Blanks, ${ }^{1}$ F. Richards, ${ }^{2}$ F. Beltrán, ${ }^{3}$ R. Collins, ${ }^{4}$ E. Álvarez, ${ }^{5}$ \\ G. Zea Flores, ${ }^{5}$ B. Bauler, ${ }^{1}$ R. Cedillos, ${ }^{6}$ M. Heisler, ${ }^{7}$ \\ D. Brandling-Bennett, ${ }^{3}$ W. Baldwin, ${ }^{1}$ M. Bayona, ${ }^{8}$ R. Klein, ${ }^{9}$ and \\ M. Jacox ${ }^{1}$
}

\begin{abstract}
The decision in 1987 by the pharmaceutical firm Merck E Co. to provide Mectizan ${ }^{\circledR}$ (ivermectin) free of charge to river blindness control programs has challenged the international public health community to find effective ways to distribute the drug to rural populations most affected by onchocerciasis. In the Americas, PAHO responded to that challenge by calling for the elimination of all morbidity from onchocerciasis from the Region by the year 2007 through mass distribution of ivermectin. Since 1991, a multinational, multiagency partnership (consisting of PAHO, the endemic countries, nongovernmental development organizations, the Centers for Disease Control and Prevention in Atlanta, Georgia, as well as academic institutions and funding agencies) has developed the political, financial, and technical support needed to move toward the realization of that goal. This partnership is embodied in the Onchocerciasis Elimination Program for the Americas (OEPA), which is supported by the River Blindness Foundation (RBF) and now by the Carter Center. OEPA was conceived as a means of maintaining a regional initiative to eliminate what is otherwise a low priority disease.

Since its inception in 1993, the OEPA has provided more than US\$ 2 million in financial, managerial, and technical assistance to stimulate and/or support programs in Brazil, Colombia, Ecuador, Guatemala, Mexico, and Venezuela, so as to take full advantage of the Merck donation. Now halfway into a five-year, US\$ 4 million grant provided through the InterAmerican Development Bank, the OEPA's capacity to support the regional initiative is assured through 1999.
\end{abstract}

1 Formerly with the River Blindness Foundation, Atlanta, Georgia.

2 Carter Center, Atlanta, Georgia. Mailing address: Global 2000 River Blindness Program, Carter Center, One Copenhill, Atlanta, GA 30307, USA. Telephone: (770) 488-4511; fax: (770) 488-4521; E-mail: Fxr1@cdc.gov

3 Pan American Health Organization, Washington, DC, USA.

4 University of Arizona, Tucson, Arizona, USA.

5 Onchocerciasis Elimination Program for the Americas, Guatemala City, Guatemala.

6 San Salvador, El Salvador.

7 Mectizan ${ }^{\circledR}$ Donation Program, Atlanta, Georgia, USA.

8 Nova Southeastern University, Fort Lauderdale, Florida, USA.

9 Centers for Disease Control and Prevention, Atlanta, Georgia, USA.
Onchocerciasis is a disease caused by Onchocerca volvulus, a parasitic worm transmitted by the bite of tiny black flies of the genus Simulium. These black flies breed in fast-flowing streams and rivers, whence the term "river blindness," which is the common name for the ocular morbidity found in persons residing close to rivers. Humans become infested when the parasite is inoculated by the bite of an infected black fly. The larvae develop into mature worms that dwell in the skin and connective tissue. Fertil- ized adult female worms release millions of microscopic embryos (microfilariae) that migrate through the skin and into other body organs, including the eye. The microfilariae damage the skin and the eyes and can cause dermal disfigurement, intense itching, visual impairment, and blindness (1).

In October 1987, the American pharmaceutical firm Merck \& Co. decided to donate, free of charge and indefinitely, millions of dollars worth of Mectizan ${ }^{\circledR}$ (ivermectin), the first riverblindness drug suitable for mass ad- 
ministration without the fear of adverse reactions (2-4). This decision was reached upon recognizing that the populations who could most benefit from ivermectin were also the least able to afford the drug. Since ivermectin, however, is not curative-it kills microfilariae but not the adult worms-ivermectin delivery programs must provide the drug regularly (once or twice a year as a single oral dose) to prevent ocular morbidity from developing and to reduce or eliminate most dermal morbidity.

Onchocerciasis ranks fourth among the causes of blindness and visual impairment in developing countries. According to $\mathrm{WHO}$, of an estimated 17.7 million people who are infested, 270000 are blind and another 500000 have severe visual impairment. Approximately 123 million people live in endemic areas worldwide and are therefore at risk of infection (1). Although the overwhelming majority of onchocerciasis sufferers live in Africa, the disease also occurs in small areas situated in six countries in the Americas: Brazil, Colombia, Ecuador, Guatemala, Mexico, and Venezuela (see Figure 1) (1, 5-7). The current WHO Expert Committee estimates of Latin Americans living in endemic areas and thus at risk of infection is 4.7 million (1), although according to more recent estimates, about 1.6 million people are at risk (7). Epidemiological information, however, is still incomplete for the Region, particularly in Brazil and Venezuela. For decades, the control method offered by the ministries of health in endemic parts of Guatemala and Mexico has been nodulectomy (surgical removal of subcutaneous adult worm clusters). In Mexico, diethylcarbamazine-a microfilaricidal drug sometimes associated with severe adverse reactions-was also distributed in mass campaigns. Addition of insecticides to streams to kill the larval stages of black flies, until recently the most widely used intervention for controlling onchocerciasis in West Africa, was not an alternative in many Latin American countries due to the high cost and great difficulty of regularly treating the small streams where many vector species breed $(5,6)$. Nevertheless, Mexico (in the 1950s) and Guatemala (in the 1970s) were able to implement successful vector control activities using pesticides in some endemic areas. Thus, the provision of the drug gave the public health community in the Americas a new, safe, and low-cost intervention to relieve human suffering.

Globally, the challenge to distribute ivermectin has stimulated the creation of new coalitions and partnerships to assemble the resources needed for getting the drug to remote tropical locations where the manifestations of onchocerciasis are most severe (3). Among these new initiatives is a multiagency coalition in the Americas dedicated to the use of ivermectin to completely eliminate onchocerciasis as a public health problem in the region by the year 2007. This initiative has come to be known as the OEPA, the Onchocerciasis Elimination Program for the Americas. The following is a description of the events leading to the creation of the OEPA and its structure, function, accomplishments, and challenges for the future.

\section{A REGIONAL PARTNERSHIP CREATES A REGIONAL PROGRAM}

By 1990, three years after the donation announcement, the ministries of health of Ecuador, Guatemala, and Mexico had implemented pioneering efforts at ivermectin distribution projects. In Guatemala, the program was in partnership with local and international nongovernmental development organizations (NGDOs) and health agencies that included the International Eye Foundation, the Guatemalan National Committee for the Blind and Deaf, Guatemala's Universidad del Valle, WHO, the University of Arizona, and the Centers for Disease Control and Prevention $(C D C)$ in the United States. In Ecuador, the partnership included Vozandes Hospital and Christoffel Blindenmission. No programs to distribute ivermectin were yet active in Brazil, Colombia, or Venezuela.
The XXIII Pan American Sanitary Conference, which took place in September 1990, noted the considerable progress made toward eliminating polio from the Americas and called for the identification of diseases that might be eliminated by or near the turn of the century. The Conference (in its Resolution XVI, Section $4 \mathrm{~b}$ ) requested PAHO to establish mechanisms to determine the feasibility of eliminating onchocerciasis, leprosy, Chagas' disease, nonvenereal treponematoses, iodine deficiency, and xerophthalmia due to vitamin A deficiency. The resolution stated that if elimination of one or more of these conditions was indeed feasible, PAHO should prepare and submit a plan of action for a regional elimination initiative (8).

\section{Feasibility of eliminating onchocerciasis from the Americas: report of the Inter-American Conference on Onchocerciasis ‘91}

In April 1991, PAHO organized the first regional Inter-American Conference on Onchocerciasis (IACO '91) to bring together experts in onchocerciasis and other parties interested in discussing new opportunities for controlling or eliminating onchocerciasis. This meeting in Guatemala City and Tapachula, Mexico, was in response to the call for a report on the feasibility of eliminating onchocerciasis using ivermectin. PAHO's financial partner for IACO '91 was the River Blindness Foundation, which had just been established by John and Rebecca Moores with the sole purpose of attaining global control of onchocerciasis. Another participant in the organization of IACO '91 was the Mectizan Donation Program (through the Task Force for Child Survival and Development), which sought to stimulate ivermectin distribution initiatives throughout endemic parts of Africa and the Americas. All the ministries of health of the six endemic countries in the Americas sent representatives to IACO '91. Also present were representatives from the United States Agency for International 


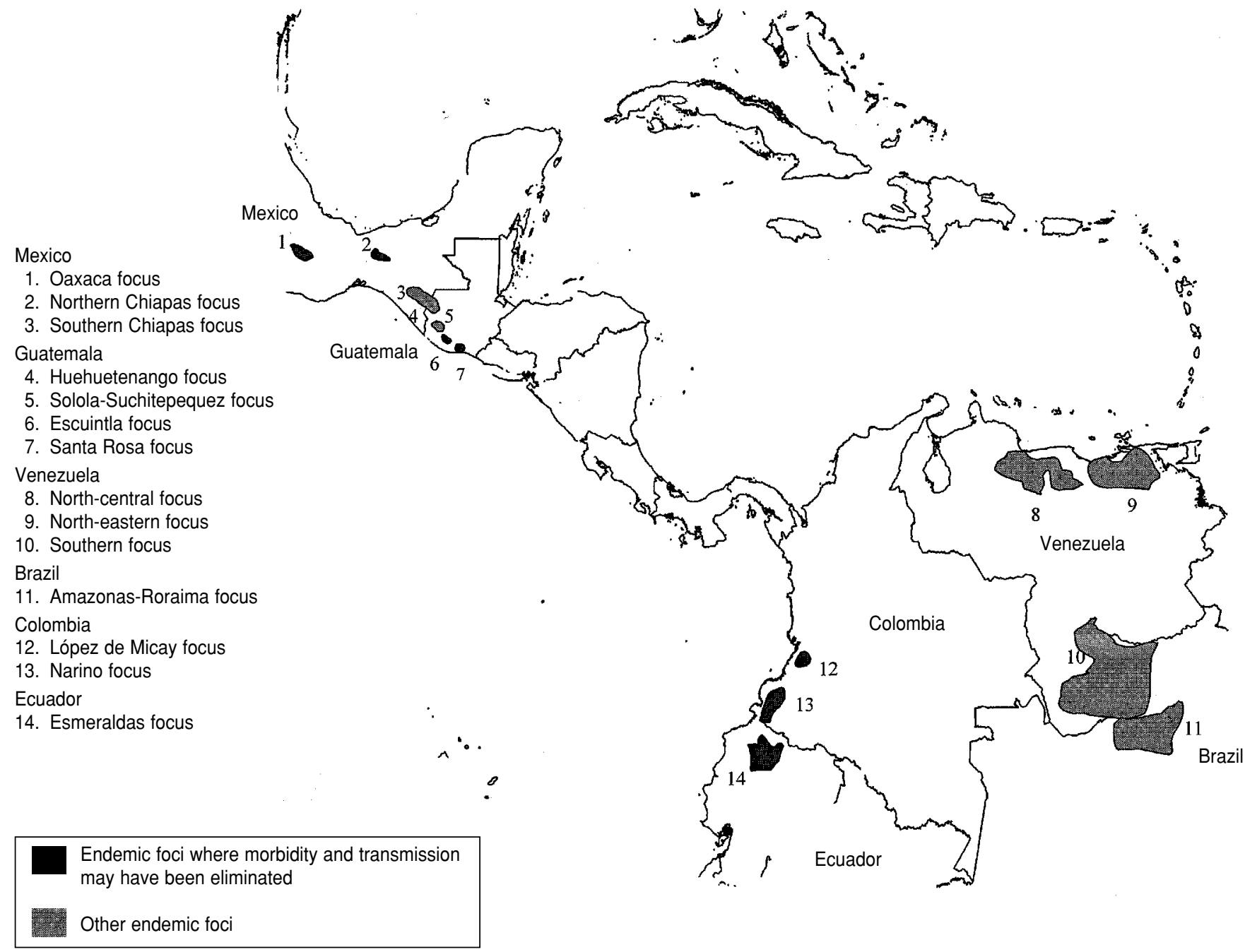

Sources: Weekly Epidemiological Record 1996;71:278 and WHO Technical Report 852, 1995.

Development (USAID), the CDC, the Government of Spain, and NGDOs interested in primary eye care (Helen Keller International, Christoffel Blindenmission, and the International Eye Foundation). After many scientific presentations and deliberations, several key conclusions (below) influenced the course of the regional initiative for the next 5 years (9).

Elimination of onchocerciasis from the Americas. Based on the available scientific evidence, morbidity from onchocerciasis can be eliminated from the Americas using ivermectin community-based treatment. Furthermore, the international momentum generated by the Merck donation provided the window of opportunity needed to fund such an initiative. Spurred by the free provision of ivermectin, availability of resources from the RBF and USAID, and growing international support for elimination/eradication programs, IACO ‘91 urged PAHO and the ministries of health of the endemic countries to provide ivermectin to the entire population at risk for onchocerciasis. The scanty epidemiological data presented at IACO ‘91 allowed only a rough estimate of four million persons living at risk for infection and morbidity in the Americas. Thus, IACO '91 called for a special focus on improved epidemiological characterization of the 14 known endemic areas (see Figure 1) in order to target those communities most affected by the disease ("high risk" or "hyperendemic communities" having a burden of cutaneous microfilariae $\geq 60 \%$ ).

A regional approach strategy. Morbidity elimination in the Americas would be most effective through a 
regional approach for several reasons. First, ministries of health in the six affected countries would be unlikely to give a national onchocerciasis elimination initiative high priority. River blindness was neither prevalent enough nor life-threatening enough to result in focused budgetary or programmatic attention by health authorities. A regional initiative, however, could provide the critical mass of interest needed to draw both political and economic support and the necessary human talent to a "nonpriority" program. Second, the global focus on onchocerciasis was on Africa; only a regional elimination effort in the Americas could provide visibility and importance to the American onchocerciasis problem, and thus garner financial support from large donors, such as the World Bank, the Inter-American Development Bank, UNICEF, USAID, and ministries of health in all affected nations. Third, because of the lack of expertise in onchocerciasis, a regional approach was necessary to garner the skills needed to establish sound national programs. Fourth, onchocerciasis occurred at cross-border foci shared by all countries (Mexico-Guatemala, Colombia-Ecuador, Venezuela-Brazil). A regional mechanism for reporting program activities might stimulate the international exchange of standardized information and coordinate the treatment of migratory populations.

Ivermectin for interrupting transmission in Guatemala and Mexico. Results presented at IACO '91 of a project sponsored by the UNDP/World Bank/WHO Special Programme for Research and Training in Tropical Diseases (TDR) in Guatemala (where the major vector species, Simulium ochraeceum, is a relatively poor transmitter of onchocerciasis) showed that ivermectin treatment provided every 6 months could interrupt transmission of the infection, even in hyperendemic communities $(10,11)$. Such interruption for a long enough time (the life-span of the O. volvulus adult worms is about 10 years) could result in actual eradication of onchocerciasis. Therefore,
IACO '91 recommended that ivermectin be mass distributed to interrupt transmission when possible and advised administration every 6 months (rather than annually) in Guatemala and Mexico. A further recommendation was that more entomologic research be carried out in Brazil, Colombia, Ecuador, and Venezuela to determine if ivermectin was capable of transmission elimination there as well.

\section{Resolution XIV of the XXXV Directing Council of PAHO}

With a consensus from IACO ' 91 that elimination of onchocerciasis was feasible, PAHO staff, following the directive of the XXIII Pan American Sanitary Conference, worked with regional consultants to prepare a Multinational Strategic Plan of Action for onchocerciasis elimination. The overall goal of the plan was "elimination of the pathological manifestations of the disease, and the interruption of transmission in selected foci. ..." (12). The challenges presented in the plan included:

- Identification of communities and populations needing ivermectin

- Monitoring of ivermectin treatment of these communities and populations

- Periodicity and sustainability of treatment activities

- Certification of morbidity elimination (by the year 2007)

- Certification of transmission elimination in certain foci (by the year 2007)

- Examination of the feasibility of parasite (species) eradication from some foci or perhaps the entire Region.

The first step was a call for each of the six endemic countries to prepare national action plans intended to 1) improve epidemiological information so that programs could determine where ivermectin should be distributed; 2) apply regionally determined standards for diagnosis, treatment, epidemiological surveillance, and health education; and 3) share epide- miological, treatment, and other related data at the regional level so that the progress toward elimination could be monitored. Lastly, the Plan of Action called for an international coalition to work toward strengthening the national control programs politically, financially, and technically.

The Plan of Action was submitted to all regional ministers of health in September 1991 at the XXXV Directing Council of PAHO meeting in Washington, D.C. In Resolution XIV, the ministers agreed to "eliminate onchocerciasis as a public health problem in the Americas" by the year 2007 (13). The resolution urged all Member States to "foster the necessary collaboration and coordination between the different levels of the public sector, and between it and the private sector, for the completion and execution of updated plans of action to prevent, control and maintain surveillance of . . . onchocerciasis. . . ." $(13,14)$. The mandate for eliminating onchocerciasis morbidity from the Americas was issued, and a regional strategy defined to reach that goal. The remainder of 1991, however, saw little to no expansion of ivermectin programs in Ecuador, Guatemala, and Mexico, and no initiation of ivermectin distribution in Brazil, Colombia, and Venezuela.

\section{US\$ 1 million pledged by the River Blindness Foundation and formation of the Strategic Planning Council}

Concerned with the lack of progress toward the goal of Resolution XIV, an ad hoc strategic planning group consisting of representatives from $\mathrm{PAHO}$, the River Blindness Foundation, the Mectizan Donation Program, CDC, and other interested parties met at PAHO Headquarters in January 1992. It was concluded that a Strategic Planning Council should be formed to serve as an advocate and coordinating group for the elimination of onchocerciasis from the Americas. The Strategic Planning Council (SPC) was to consist of members of the partnership and provide a forum that would lead to 
joint action. At the first SPC meeting in March 1992, the River Blindness Foundation announced its intention to commit US\$ 1 million as seed funding to set the regional initiative in motion. The money was to be held in an RBFcontrolled trust fund, with the SPC determining the criteria and standards for allocating funds to help each country develop and implement a plan of action consistent with the regional strategy. With RBF funding in hand, the SPC outlined a strategy for launching the initiative.

It was hoped that the regional initiative would move from the planning stage to achievement of ivermectin distribution in all six countries by 1993 . As a first step, regional norms were developed for establishing baseline indices and standard components of ivermectin distribution programs. A series of task force meetings of experts led to normative planning. The first such meeting, held in March 1992, produced standard guidelines for the epidemiologic characterization of endemic areas and evaluation of impact. Other meetings followed (see Table 1). The second step was to stimulate the production of official national plans of action for the six national onchocerciasis elimination programs. During the period April through June 1992, SPC delegations traveled to all six countries to meet with key political and ministerial figures to request their help in the preparation of plans consistent with the new regional norms. The delegations explained PAHO Resolution XIV calling for a regional initiative to eliminate onchocerciasis with sustainable ivermectin distribution as the key strategy. The delegation urged that national plans and budgets be developed in time for presentation at the second Inter-American Conference on Onchocerciasis to be held later that year. Working meetings in Ecuador, Guatemala, Mexico, and Venezuela helped national experts and responsible Ministry of Health officials to come together to work on the plans.

\section{Inter-American Conference on Onchocerciasis ' 92 and the Onchocerciasis Elimination Program for the Americas}

The goal of the second Inter-American Conference on Onchocerciasis

TABLE 1. Key meetings and workshops of the Regional Initiative to Eliminate Onchocerciasis from the Americas

1991 IACOa '91: Feasibility of a Regional Onchocerciasis Elimination Program, Guatemala City,
Guatemala and Tapachula, Mexico
TASKFORCE: The epidemiologic characterization of onchocerciasis, Washington, DC, USA
TASKFORCE: Health education and social communication in onchocerciasis control, June
1992, Atlanta, Georgia, USA
TASKFORCE: Ophthalmological assessment of onchocerciasis, Antigua, Guatemala
IACO '92: Presentation of National Plans, Quito, Ecuador
TASKFORCE: Operationalization of geographic information systems in the regional programs,
Puerto Ayacucho, Venezuela
IACO '93: The Onchocerciasis Elimination Program for the Americas (OEPA), Puerto
Ayacucho, Venezuela
IACO '94: International (cross-border) issues: The Need for Binational Plans of Action,
Washington, DC, USA
WORKSHOP: Onchocerciasis transmission modeling, Guatemala City, Guatemala
IACO '95: Health Education and Indigenous Cultures, Brasilia, Brazil
WORKSHOP: The epidemiologic characterization of onchocerciasis: revision of 1992
guidelines by national program representatives, Quito, Ecuador
WORKSHOP: Geographic Information Systems training, Guatemala City, Guatemala
IACO '96: Certification of Elimination in the Americas: Towards Better Data, Oaxaca, Mexico
WORKSHOP: Administration of Inter-American Development Bank grants, Guatemala City,
Guatemala
IACO '97: Drafting Criteria for Certification of Elimination in the Americas

a Inter-American Conference on Onchocerciasis.
(IACO '92), which took place in Ecuador in September of 1992, was the approval of national plans and budgets. Despite the Strategic Planning Council's efforts of the previous months, however, most plans required further work and could not be fully funded. In addition, it was obvious that the SPC would face increasingly complicated and varied expectations, technical needs, and financial proposals. Because the SPC consisted of some 20 members serving on a voluntary basis, it was incapable of responding to the growing challenges of establishing the regional program. The Strategic Planning Council concluded at its IACO '92 meeting that a part of the RBF donation should be used to establish two staff positions to serve as its secretariat and to travel as advocates of Resolution XIV of the Directing Council of PAHO. Thus, the SPC announced to the assembled IACO ' 92 body the launching of the office of the Onchocerciasis Elimination Program for the Americas. The OEPA headquarters was established in Guatemala in January 1993, and its first director and expert advisor immediately began visiting the six endemic countries to facilitate the preparation of more thorough national plans and budgets. At the same time, a vigorous fundraising campaign for the OEPA was initiated by the River Blindness Foundation.

\section{The OEPA and its coordinating bodies}

It was decided not to spend the time or money to establish OEPA as a "legal" NGDO. Indeed, the OEPA was not conceived to be an NGDO, but rather a timely mechanism to establish and maintain the regional elimination program, a secretariat for the multinational/multiagency coalition, and a technical and financial support resource to the national elimination programs. The River Blindness Foundation agreed to serve as the OEPA's "parent" NGDO organization in an administrative capacity (i.e., to make contracts, establish accounts, and apply for grant monies), and to employ 
and supervise OEPA staff. The SPC, however, was responsible for technical and programmatic decisions. Prompt assistance for day-to-day decisionmaking by OEPA staff was handled by the Program Coordinating Committee (PCC), a smaller body established by the SPC in February 1993. The PCC has met twice annually since then (on one occasion at the IACO session). In late 1995, the SPC agreed to disband and merge all remaining representation functions into the PCC and annual IACO meetings.

The PCC is currently charged with conducting an ongoing and detailed review of OEPA technical activities. The PCC consists of nine members, with institutional representation of the RBF/Carter Center (two members), PAHO (1), the CDC (1), a ministerial (or national program) appointed representative from one of the six endemic countries, and four "at-large" members who are nongrantee participants (tropical disease and public health professionals) in the program and who can serve up to two 2-year terms. Only one-year terms are allowed for the national program representatives to allow more rapid rotations (and thus equal representation) on the PCC.

\section{Technical support from the Inter- American Development Bank}

Seeking additional funding for the regional initiative has been an important activity of the OEPA from its inception. The key success in the fundraising campaign is a 5-year grant of US\$ 4 million from the Inter-American Development Bank, approved in June 1994, 20 months after the launching of the OEPA. IDB funding came just as the RBF trust fund was being exhausted; it resulted in a new burst of enthusiasm due to the dramatic increase in OEPA activities and viability. IDB funds are given to strengthen the technical expertise, training, and equipment components common to all six countries. Permitted expenditures are in areas of epidemiologic surveillance and analysis, behavioral sciences, health education programs, information systems, and program evaluation. Three long-term consultants (professionals in epidemiology, health education/social science, and information systems) were recruited in 1994 and were in place at the OEPA headquarters by mid-1995.

IDB elected to become a partner because of certain appealing elements in the OEPA initiative: 1) a "regional" approach; 2) an "elimination deadline" for project completion; 3) a strong technical and evaluative orientation; and 4) standardized reporting, measurable goals and objectives, and maximized regional use of information. The grant was also attractive because clearly defined "cost-sharing" components pointed to a "real" partnership with PAHO, NGDOs, donors, and governments. IDB monies are calculated to be only about $20 \%$ of the actual expenditures required by the regional elimination program, and these monies may not be used to support the programmatic aspects of ivermectin distribution. Each national program must provide required elements in cash and kind (salaries or transport, for example) to support ivermectin delivery.

\section{The Carter Center}

The Carter Center has long been involved in the campaign against river blindness. In 1987, the year of the announcement of the donation of ivermectin, its then executive director agreed to chair a Mectizan ${ }^{\circledR}$ Expert Committee to review, approve, and monitor the global ivermectin donation process. As a result of sustained interests at the Carter Center, in early 1995 negotiations began to combine the $\mathrm{RBF}^{\prime}$ 's programs with those of the Carter Center's Global 2000 program, which had considerable resources and reputation in Africa as a result of the successful guinea worm eradication campaign. The Carter Center, as the surviving institution, would provide a stable, internationally-recognized base and additional programmatic expertise that could ensure the successful accomplishment of the RBF mission. In April 1996, Global 2000 acquired essentially all of RBF's programs and activities and established the Global 2000 River Blindness Program (GRBP). As part of the acquisition, the Carter Center assumed the role as the administrative parent of OEPA, and thus as executing agency of the IDB and other grants. The OEPA's office under the Carter Center is located in Guatemala City.

\section{Accomplishments of the Onchocerciasis Elimination Program for the Americas}

The OEPA initiative has proven that regional partnerships can produce the critical mass to draw political, technical, and economic support for ivermectin distribution. By 1996, all six countries were distributing ivermectin under national plans of action, treating more than 195000 persons, and reaching $98 \%$ of the 345 known hyperendemic communities in the region. Representatives of the six countries where onchocerciasis is endemic in the Americas have met annually since 1991 in IACO meetings cosponsored by PAHO. These meetings have maintained the momentum and the community of the regional effort. IACO and task force meetings provide forums to report treatment and evaluation activities; hear presentations of new research findings related to onchocerciasis; and review, revise, and discuss general policy issues and regional normative recommendations. All six governments now provide infrastructure, physical facilities, communications, transportation, and salary support for central and local staff whose duties include onchocerciasis elimination. As part of the IDB grant process, all six governments provided letters indicating their commitment to their onchocerciasis programs, and since 1994 national financial support to the country programs has totaled over $\$ 3$ million. A binational team of Colombian and Ecuadorean health 
workers carried out a joint epidemiological exercise on the shared border of their countries, Guatemala and Mexico have reached several agreements in which onchocerciasis has been specifically mentioned, and Brazil and Venezuela have an interinstitutional plan of action related to ivermectin distribution activities in the migratory populations who cross their shared borders.

\section{CHALLENGES FOR THE FUTURE}

A movement to eliminate morbidity from onchocerciasis in the Americas was stimulated by the donation of ivermectin, designed in a multinational plan of action, sanctioned by Resolution XIV of the Directing Council of PAHO, and launched by the River Blindness Foundation in a gamble of a $\$ 1$ million seed grant. The OEPA maintains the initiative by serving the multiagency coalition as a means for expeditious, task-oriented action and reporting. Within the forum of a regional coalition, the OEPA has succeeded in providing financial, technical, managerial, and indeed moral support for a group of experts in nongovernmental organizations, universities, and ministries of health who endeavor to execute national elimination programs based on ivermectin distribution. Obstacles to the success of the initiative have been and remain great, and include restricted funding, repeated changes in ministry of health leadership, setbacks due to decentralization of health programs, and resistance to access and standardization of information. Yet, since its inception in early 1993, the OEPA has succeeded in nurturing a regional coalition that can now boast of ivermectin distribution activities in 98\% of all known hyperendemic communities in the Americas. The OEPA has stimulated the launching of completely new programs in Brazil, Colombia, and Venezuela; has helped resurrect the Guatemalan program after its collapse following an uncompleted national health sector de- centralization policy in 1995; has supported rigorous program evaluation and operations research in Mexico and Ecuador; and has stimulated several binational meetings and international plans to eliminate onchocerciasis. The OEPA has leveraged the original \$1 million RBF donation to generate funding of over $\$ 5$ million from other donors, most notably the Inter-American Development Bank and USAID. Lastly, OEPA profits from a committed corps of professionals volunteering their time to serve on coordination committees that provide nonaligned and transparent oversight for regional goal setting and equitable decision making.

For the future, OEPA must evolve in response to the changing realities of the experiment that led to its creation. The Carter Center will bring to OEPA a new focus on better reporting of the numbers of persons and communities being treated $(7,15)$. Mounting a large campaign for rapid epidemiological assessment of northern Venezuela (where the current population at risk is crudely estimated to be 800000 ) is critical (7). Sustainability of programs must be promoted by showing that ivermectin delivery can strengthen or stimulate new primary health care infrastructure in as yet underserved areas. The OEPA and PAHO must work to identify internationally acceptable criteria that can be applied to certify onchocerciasis elimination in the 14 zones in the six countries (see Figure 1). Such criteria need to be applied soon in Oaxaca and Chamula (Zones 1 and 2), San Vicente Pacaya and Santa Rosa (Zones 6 and 7), throughout Colombia (Zones 12 and 13), and in Ecuador (Zone 14) to measure and celebrate progress and milestones toward Resolution XIV's goal $(7,15)$. Global interest is crucial to revitalize political and economic support. Finally, documentation of the interruption of transmission in the different vectors and ecological foci (as opposed to certification of elimination of morbidity) requires additional field research.

Despite the challenges for change, certain OEPA roles and responsibili- ties must remain constant. The OEPA must be oriented to rapid action, transparency in decision-making, and effective response to the challenges of field program implementation. With its PAHO partner, the OEPA must constantly remind Governments and ministries of health of their agreement on the goal of Resolution XIV to eliminate onchocerciasis as a public health problem in the Americas by the year 2007. Finally, the OEPA must diversify its financial support to remain able to supplement or bridge, when necessary, those programmatic areas not covered by the IDB grant.

If this regional initiative can maintain political and financial support, onchocerciasis in the Americas will be eliminated through ivermectin distribution. Then, as the Americas led the way in polio eradication in 1991 (16), so will they lead the way to elimination of onchocerciasis-related morbidity by 2007 . Indeed, with continued momentum and funding, we anticipate achievement of the loftier goals of transmission interruption and perhaps eradication.

Acknowledgments. The authors wish to thank the OEPA Community and Working Group: Ecuador-M. Espinel, R. Guderian, T. Mancero, G. Rivadeneira; Colombia-A. Corredor, R. S. Nicholls; Venezuela-C. Botto, J. Convit, I. Petralanda, E. Pieruzzi, R. Quiroga; Guatemala-F. Beltranena, J. Castro, G. Hernández-Polanco, R. Luján, J. O. Ochoa, R. Zea; Brazil-G. Coelho, J. B. Furtão Vieira, V. PyDaniels; Mexico-C. Álvarez-Lucas, F. Chávez Peón, A. Martín-Tallaeche, R. Rivas-Alcalá (deceased), J. RodríguezDomínguez; OEPA/PCC-V. Álvarez, A. Chacón, F. Clark, J. Ehrenberg, A. L. Morales, M. Richards, R. Sáenz, J. C. Solares, F. Westchott; PCC-A. D'Alessandro; PAHO/WHO-J. Arias, A. Bañuelos, I. Barragán, L. Cabrera, J. A. Casas, S. Corber, J. Fernández de Castro, J. Finkelman, F. García Scarponi, C. Lombardi, H. Málaga, R. Oceguera (deceased), J. M. Paganini, F. Paniagua, V. Pou-Howley, H. Remme, T. 
Sánchez, G. Schmunis, J. C. Silva, J. M. Sotelo, J. Tejeda, J. R. Unda, M. Valcárcel, B. Whalley, F. Zicker, R. Zimmerman; IDB-R. Badía, J. M. Fariña, M. A. García, I. Pastor, J. Rojas, G.
Tate; CDC-R. Kaiser (deceased); The Carter Center-A. Agle, D. Hopkins, J. Lawrence, R. Robinson; RBF-Y. Dunleavy, J. Lammert, E. McKinney, J. Moores, W. Walsch; USAID-C.
Bowes, D. Carrol; Other-E. Cupp, R. Gern, A. O. Lucas, M. Sauerbrey, R. Semba, I. Tada, C. Witte; and Mectizan $^{\circledR}$ Donation Program-B. Dull, W. Foege, S. Meredith.

\section{REFERENCES}

1. World Health Organization Expert Committee on Onchocerciasis: fourth report. Geneva: WHO; 1995. (Technical Report Series 852).

2. Greene BM, Taylor HR, Cupp EW, Murphey $\mathrm{RP}$, White AT, Aziz MA, et al. Comparison of ivermectin and diethylcarbamazine in the treatment of onchocerciasis. N Engl J Med 1985;313:133-138.

3. Anonymous. Mectizan ${ }^{\circledR}$ (ivermectin) and the control of onchocerciasis: strengthening the global impact. Summary proceedings of the symposium, New York City, September 23, 1992. Rahway, NJ: Merck \& Co; 1992.

4. Taylor HR, Greene BM. The status of ivermectin in the treatment of human onchocerciasis. Am J Trop Med Hyg 1989;41:460-466.

5. Ramírez Pérez J. Human onchocerciasis foci and vectors in the American tropics and subtropics. Bull Pan Am Health Organ 1986;20:381-402.

6. Shelly AJ. Vector aspects of the epidemiology of onchocerciasis in Latin America. Ann Rev Entomol 1988;30:337-366.

7. World Health Organization. Onchocerciasis, progress towards elimination in the Americas. Wkly Epidemiol Rec 1996;71: 277-279.
8. Pan American Health Organization. Pan American Sanitary Conference Regional Committee Meeting. Resolution XVI: calendar of possible eradication targets to be achieved in the Americas between now and the year 2000. 27 September 1990. Washington, DC: PAHO; 1991.

9. Pan American Health Organization. Report of the First Interamerican Conference on Onchocerciasis (IACO 91): April 26 to May 1, 1991, Tapachula, Mexico, and Guatemala City, Guatemala.

10. Collins RC, Gonzales-Peralta C, Castro J, ZeaFlores G, Cupp M, Richards F, et al. Ivermectin: reduction in prevalence and infection intensity with Onchocerca volvulus following biannual treatments in five Guatemalan communities. Am J Trop Med Hyg 1992;47:156-169.

11. Cupp EW, Ochoa JO, Collins RC, Cupp MS, Gonzales-Peralta C, Castro J, et al. The effects of repetitive communitywide ivermectin treatment on transmission of Onchocerca volvulus in Guatemala. Am J Trop Med Hyg 1992;47:170-180.

12. Pan American Health Organization. Multinational strategic plan of action toward onchocerciasis elimination in the Americas. 1991. (Annex VI of PAHO Directing Council, XXXV meeting, Agenda Item 5.4. Report on the status of the eradication/elimination of certain diseases from the Region. Washington, DC, September 1991, CD35/16)

13. Pan American Health Organization. PAHO Directing Council, XXXV meeting. Agenda Item 5.4: Report on the status of the eradication/ elimination of certain diseases from the Region. Washington, DC, September 1991, CD35/16 (Eng.).

14. Anonymous. Status of the eradication/elimination of certain diseases from the Americas. Bull Pan Am Health Organ 1992;26:80-86.

15. World Health Organization. Annual Onchocerciasis Report from the Inter-American Conference on Onchocerciasis in Oaxaca, Mexico. Wkly Epidemiol Rec 1997;72:215-218.

16. Centers for Disease Control and Prevention. Certification of poliomyelitis eradication: the Americas, 1994. MMWR 1994;43:720-722.

Manuscript received on 19 May 1997. Revised version accepted for publication on 20 October 1997.
RESUMEN

Programa de Eliminación de la Oncocercosis para las Américas: historia de solidaridad
La decisión tomada en 1987 por la Merck \& Co., fabricante de productos farmacéuticos, de proveer Mectizan ${ }^{\circledR}$ (ivermectina) gratuitamente a los programas de control de la oncocercosis ha obligado a la comunidad sanitaria internacional a buscar formas de distribuir el medicamento a las poblaciones rurales que se ven más afectadas por la enfermedad. En las Américas, la OPS respondió al reto con un llamado a eliminar de la Región toda morbilidad por oncocercosis para el año 2007 mediante la distribución de ivermectina al público. Desde 1991, una alianza multinacional de diversas entidades (la OPS, países con oncocercosis endémica, agencias de desarrollo no gubernamentales, los Centros para el Control y la Prevención de Enfermedades en Atlanta, Georgia, instituciones académicas y agencias de financiamiento) ha generado el apoyo político, económico y técnico necesario para tratar de alcanzar esa meta. Esta alianza está representada por el Programa de Eliminación de la Oncocercosis en las Américas (OEPA), subvencionado por la Fundación Ceguera de los Ríos y actualmente por el Centro Carter. El OEPA se creó como iniciativa de alcance regional destinada a eliminar una enfermedad que no merece atención prioritaria. Desde su aparición en 1993, el OEPA ha aportado más de US\$ 2 millones en ayuda económica, administrativa y técnica para fomentar y subvencionar programas en Brasil, Colombia, Ecuador, Guatemala, México y Venezuela, logrando así aprovechar al máximo la donación de la Merck \& Co. Ahora que hemos llegado a la mitad de una subvención de 5 años y US\$ 4 millones aportada por el Banco Interamericano de Desarrollo, se sabe que el OEPA tiene la capacidad para apoyar la iniciativa regional hasta fines de 1999. 